\title{
Mineral Liberation: A Case Study for Buzwagi Gold Mine
}

\author{
Alphonce Wikedzi ${ }^{1 *}$ and Thomas Leißner ${ }^{2}$ \\ ${ }^{1}$ University of Dar es Salaam, School of Mines and Geosciences, Department of Mining and \\ Mineral Processing Engineering, P. O. Box 35131, Dar es Salaam, Tanzania. \\ *Corresponding author, e-mail: alpho20012001@gmail.com \\ ${ }^{2}$ TU Bergakademie Freiberg, Institute of Mechanical Process Engineering and Mineral \\ Processing, Agricolastraße 1, 09599 Freiberg, Germany. \\ E-mail: thomas.leissner@mvtat.tu-freiberg.de \\ Received 28 Apr 2021, Revised 13 Jul 2021, Accepted 20 Jul 2021, Published Aug 2021 \\ DOI: https://dx.doi.org/10.4314/tjs.v47i3.2
}

\begin{abstract}
Buzwagi Gold Mine (BGM) process plant was designed such that, after secondary grinding, gold and copper are recovered by flotation. However, the flotation circuit had been inefficient, and as a result, cyanidation of flotation tailings is currently conducted to improve gold recovery. The inefficient flotation is suspected to be due to mineralogical variations of ores treated. Hence, mineral liberation characteristics of three ore blends treated by BGM were investigated by automated Scanning Electron Microscope (SEM) whereby five fractions (i.e. $-1+0.5 \mathrm{~mm},-0.5$ $+0.25 \mathrm{~mm},-0.25+0.125 \mathrm{~mm},-0.125+0.063 \mathrm{~mm}$ and $-0.063 \mathrm{~mm}$ ) were used. It was found that pyrite-pyrrhotite is the major valuable phase and the host of gold. Furthermore, pyrite-pyrrhotite was liberated at relatively coarse size (i.e. approx. 200-400 $\mu \mathrm{m}$ ). Additionally, quartz, feldspar, muscovite and biotite-chlorite were the main gangue phases. Pyrite-pyrrhotite grain size distribution was coarser than most gangue minerals in the ore blends, indicating that most of the milling energy was lost in grinding of gangue phases. Since gold host phase (pyrite-pyrrhotite) was liberated at coarser sizes, it was concluded that the efficiency of gravity circuit could not be affected. However, the flotation process will still require finer feed (i.e. $\leq 125 \mu \mathrm{m}$ ) for its efficiency.
\end{abstract}

Keywords: Mineral liberation; Gold ore blends; Flotation Performance; Pyrite-pyrrhotite; Automated Mineralogy.

\section{Introduction}

The main purpose of any mineral beneficiation plant is to separate the valuable components of the ore from the worthless parts, and to concentrate them so that a saleable product is obtained. The concentration steps are usually preceded by a comminution stage whose purpose is to break the ore to a particle size small enough to free or liberate the valuable components from the gangue (NapierMunn et al. 1996, Wills and Finch 2016). It is well known that comminution constitutes a large part of the costs in mineral processing: it is therefore important to avoid overgrinding while sufficiently liberating the valuable minerals (Bérubé and Marchand 1984). The current practice is to try to obtain a product with a steep particle size distribution at the grinding stage in order to improve separability of the material. Unfortunately, the textural properties of the valuable mineral phases may vary naturally in the orebody and such a strategy may involve either poor or excessive liberation. The degree of mineral liberation 
required must therefore be verified periodically, or at least each time when the characteristics of the mineralization are suspected to have changed (Bérubé and Marchand 1984).

The main objective of comminution is to achieve liberation at the coarsest possible particle size. If such a goal is achieved, then not only is energy saved but also by reducing the amount of fines produced, any subsequent separation stage becomes easier and cheaper to operate, also the throughput will be increased (Wills and Finch 2016). However, effective mineral liberation remains one of the major challenges in treating modern ores, which due to the increasing complexity and smaller grain sizes, require finer grinding to achieve the necessary degree of mineral liberation (Veasey and Wills 1991, Danha 2013) .

Particle size reduction and mineral liberation are inextricably linked. If the particle size to which the rock is reduced is insufficient, then a relatively large proportion of the valuable constituents will not be extracted, leading to loss of potential revenue. If the particle size chosen is too small, an oversized and over costly plant with unnecessarily high energy costs will result. To ensure an efficient process therefore, mineral liberation and its association with size reduction should be well characterized (Morrell 1996, Napier-Munn et al. 1996).

In practice, ores are ground to an optimum grind size, determined by laboratory and pilot scale test work, to produce an economic degree of mineral liberation. The concentration process is then designed to produce a concentrate consisting predominantly of valuable minerals, with an accepted degree of locking with the gangue minerals and a middling's fraction, which may require further grinding to promote optimum release of the minerals. The tailings should be mainly composed of gangue minerals (Wills and Finch 2016).

Considering challenges of increasing ore body complexity, improving the plant throughput and process plant efficiency will not only depend on large equipment, but rather, ore feed mineralogy, texture and better control of the variance thereof (Baum 2014). Hence, substantial mineralogical characterization is required in order to avoid poor processing performance (Baum et al. 2004, Hoal et al. 2009, Evans et al. 2011, Lotter 2011, Smythe et al. 2013, Baum 2014).

Conventional optical microscopes can be used for examination of thin and polished sections of mineral samples. However, it is today increasingly common to employ quantitative automated mineral analysis using scanning electron microscopy combined with energy dispersive $\mathrm{X}$-ray analysis, such as the Mineral Liberation Analyzer (MLA) (Gu 2003, Fandrich et al. 2007), the QEMSCAN) (Gottlieb et al. 2000), and the Tescan Integrated Mineral Analyzer (TIMA), which scan polished sections using an electron beam to generate 2D mineralogical information, and $\mathrm{X}$-ray microcomputed tomography (micro CT) that allows for $3 \mathrm{D}$ visualization of particulates (Wills and Finch 2016).

The present study therefore, summarizes the ore mineralogy and mineral liberation characteristics of three (3) ore blends treated at BGM at the time when the survey sampling campaign was conducted. It also highlights on the potential impacts of mineral liberation on the downstream cyanidation and flotation processes. The mineral liberation studies were examined using an automated scanning electron microscope (SEM) technique, while the analysis of liberation data was performed using MLA Dataview (Fandrich et al. 2007).

This work is an extension of the authors' previous studies on breakage and liberation characteristics of low grade sulphide gold ore blends (Wikedzi et al. 2018) as well as operation and performance of grinding circuits (Wikedzi 2018).

\section{Materials and Methods \\ Plant survey and initial preparation of samples \\ The three ore blends used in the study (i.e.} S-1, S-2, and S-3) were obtained by a belt cut 
from the feed conveyor of the SAG mill at Buzwagi Gold Mine when the three main ore blends were treated. The three bulk samples had an average particle size of less than $200 \mathrm{~mm}$ and specific gravity of $2.8 \mathrm{~g} / \mathrm{cm}^{3}$. In addition to belt cut feed samples collected, other key plant streams (ball mill and hydrocyclone streams, refer Figure 1) were also sampled in order to understand the state of the art performance of the plant in terms of grinding efficiency.

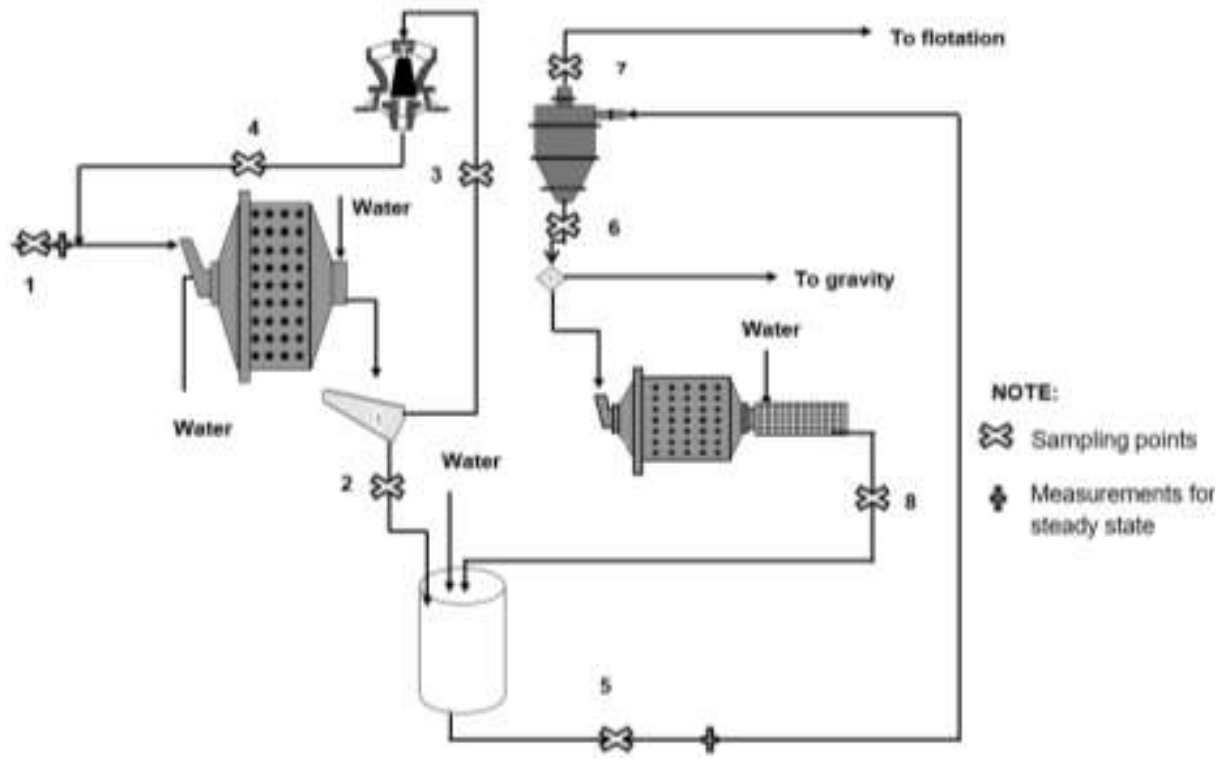

Figure 1: BGM grinding circuit flow sheet with sampling points.

Here each stream was sampled after every 15 minutes for a period of two hours, a practice recommended under steady state circuit operating conditions (Napier-Munn et al. 1996). Hence, prior to this sampling, circuit operating conditions were monitored to ensure that the plant is under steady state conditions. A total of 8 sub-samples were collected for each stream to make a composite representative sample for analysis. The mineralogical reports of the deposit revealed that gold and silver occur as inclusions in pyrite, unaltered chalcopyrite, quartz and bornite as well as free grains. Copper occurs primarily in the chalcocite-chalcopyrite replacement grains. The masses and assay data of the three bulk samples collected for the three ore blends treated at the time of the survey are presented in Table 1. The copper, silver and gold contents were determined using an Atomic Absorption Spectrometer (AAS), model AA240 (precision $<2 \%$ error).

Table 1: Masses and assay data of bulk samples as collected on site

\begin{tabular}{llll}
\hline Item & $\mathrm{S}-1$ & $\mathrm{~S}-2$ & $\mathrm{~S}-3$ \\
\hline Mass in kg & 377.50 & 341.14 & 314.94 \\
$\mathrm{Au}$ in g/t & 1.94 & 1.75 & 1.33 \\
$\mathrm{Ag}$ in $\mathrm{g} / \mathrm{t}$ & 2.36 & 3.0 & 1.90 \\
$\mathrm{Cu}$ in wt.-\% & 0.07 & 0.10 & 0.08 \\
\hline
\end{tabular}


For this study, representative sub-samples were obtained by a stage-wise crushing (with laboratory jaw and cone crushers) as well as ball milling and then splitting (riffle splitter). The general procedure is presented in Figure 2.

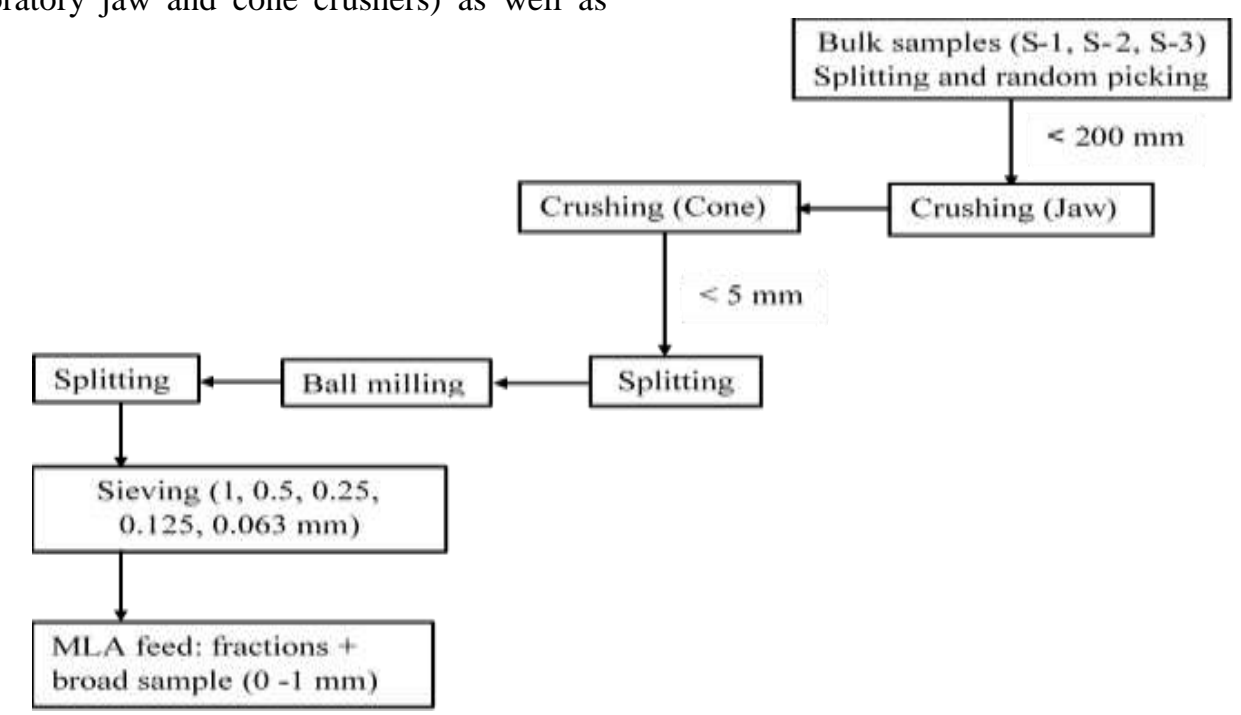

Figure 2: Preliminary sample preparation steps for mineral liberation studies.

\section{Mineral liberation analysis}

To characterize the liberation properties of the BGM ore blends, an automated mineral liberation analysis (MLA) technique was employed. Hence, ore blends samples were first prepared in a screen ball mill with $1 \mathrm{~mm}$ screen and then ground products sieved into five fractions, $-1+0.5 \mathrm{~mm},-0.5+0.25 \mathrm{~mm}$, $0.25+0.125 \mathrm{~mm},-0.125+0.063 \mathrm{~mm}$ and -0.063 $\mathrm{mm}$ which were finally subjected to automated mineralogical characterization. A broad sample from the mill discharge (i.e. $0-1 \mathrm{~mm}$ ) was also included in the MLA analysis.

The measurements were performed at the Department of Mineralogy, TU Bergakademie Freiberg, using FEI MLA 600F system (Figure
3) (Gu 2003, Fandrich et al. 2007, Sandmann and Gutzmer 2013, Sandmann 2015). Feed samples to the system were prepared as polished grain mounts using epoxy resin (Sandmann and Gutzmer 2013, Sandmann 2015, Leißner et al. 2016). Three sample splits were prepared for each fraction measured by MLA. The mounts were carbon-coated prior to measurements to obtain an electrically conducting surface. The XBSE measurement mode was employed, and with the electron beam and electron current density being set at $25 \mathrm{kV}$ and $10.0 \mathrm{nA}$, respectively. For each polished surface, between 5000 and 300,000 particle sections (refer Table 2) were analyzed.

Table 2: Number of particles analysed by MLA for the three ore blends

\begin{tabular}{cccccc}
\hline Sample & \multicolumn{5}{c}{ Size classes $(\mu \mathrm{m})$} \\
\cline { 2 - 6 } & $0-63$ & $63-125$ & $125-250$ & $250-500$ & $500-1000$ \\
\hline S-1 & 330,779 & 48,884 & 18,026 & 11,518 & 6,264 \\
S-2 & 373,306 & 63,350 & 19,629 & 11,724 & 5,163 \\
S-3 & 330,867 & 52,079 & 20,161 & 11,635 & 8,391 \\
\hline
\end{tabular}


Upon bombardment of an electron beam in a SEM, a mineral phase will backscatter electrons at an intensity defined by its average atomic number as well as release X-rays characteristic of elements that are present. The measurement of Backscattered Electron (BSE) intensities allows the segmentation of mineral phases within a single particle, while X-rays analysis of those phases allows the identification of each mineral phase. The analysis of mineral liberation data was performed by using MLA Dataview software (Fandrich et al. 2007). For the mineral grains, between 18,000 and 300,000 mineral grain counts were analyzed for each fraction as shown in Table 3.

Table 3: The number of grain counts analysed by MLA for the three ore blends

\begin{tabular}{cccccc}
\hline Sample & \multicolumn{5}{c}{ Size classes $(\mu \mathrm{m})$} \\
\cline { 2 - 6 } & $0-63$ & $63-125$ & $125-250$ & $250-500$ & $500-1000$ \\
\hline S-1 & 341,901 & 67,256 & 34,931 & 27,227 & 19,618 \\
S-2 & 386,232 & 81,693 & 35,120 & 32,487 & 18,659 \\
S-3 & 342,204 & 69,013 & 39,996 & 30,817 & 21,055 \\
\hline
\end{tabular}

A common constraint with quantitative automated SEM-based image analysis is the fact that they are based on evaluation of $2 \mathrm{D}$ sections and hence may be subjected to stereological errors (Vizcarra et al. 2010). As there is no suitable method for stereological correction available for this ore, no correction was applied. The stereological correction studies are very well covered in the work by Ueda and others (Ueda et al. 2017, 2018, Wang et al. 2018).

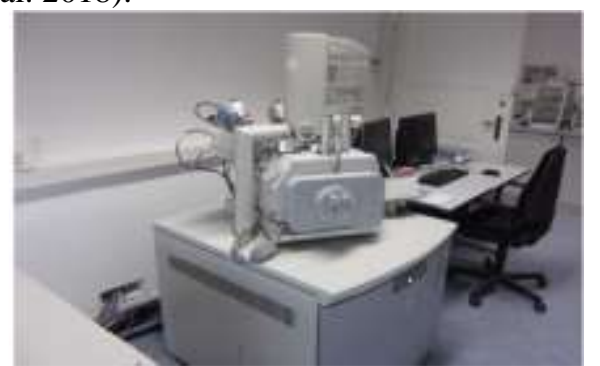

Figure 3: MLA 650 FEI system set up for mineral liberation studies.
Results and Discussion

Grinding performance evaluation based on key circuit streams

Table 4 and Table 5 show the performance indicators for the ball mill and hydrocyclones, respectively as obtained during sampling of the three ore blends at BGM. There were no significant differences in performance of the ball mill during treatment of the three ore blends. Based on the product fineness and reduction ratios, it can be seen that the ball mill operation was inefficient $\left(x_{\mathrm{P}, 80}\right.$ $>400 \mu \mathrm{m}$ vs. $125 \mu \mathrm{m}$ (design)). The poor performance of the ball mill might have been the reason for the reported poor performance of the flotation circuit as finer products from the hydrocyclone overflow which are suitable as flotation feed depends on the performance of the ball mill.

Table 4: Ball mill performance indicators

\begin{tabular}{lllll}
\hline Parameter & S-1 & S-2 & S- 3 & Design \\
\hline Ball mill feed $x_{\mathrm{F}, 80}(\mathrm{~mm})$ & 0.963 & 1.028 & 1.127 & \\
Ball mill discharge $x_{\mathrm{P}, 80}(\mathrm{~mm})$ & 0.570 & 0.419 & 0.403 & 0.125 \\
Ball mill reduction ratio $(-)$ & 1.70 & 2.45 & 2.80 & \\
Ball mill specific energy $(\mathrm{kWh} / \mathrm{t})$ & 4.77 & 5.74 & 10.73 & \\
Ball load, \% volume & 33 & 33 & - & $30-35$ \\
\hline
\end{tabular}


The results in Table 5 show that the hydrocyclone overflow product size $\left(x_{\mathrm{P}, 80}\right)$ is much coarser than the target size (i.e., $125 \mu \mathrm{m}$ ) in all surveys. In addition, feed rates during the treatment of the ore blends $\mathrm{S}-1$ and $\mathrm{S}-2$ were 10 and $18 \%$ higher than design capacity of $1462 \mathrm{t} / \mathrm{h}$, implying that hydrocyclones were overloaded. Since the ball mill products were significantly coarser than design values (Table 4), the coarse overflow size achieved could also be contributed by the inefficient ball mill.
Based on these indications from the ball mill and hydrocyclones, the reported poor performance of the flotation circuit at BGM might have also been caused by inefficient grinding in addition to the speculated ore mineralogical variations as gold particles in most sulphide ores are occluded and require milling to between 60 and $80 \%$ smaller than $75 \mu \mathrm{m}$ to be liberated (O'connor and Dunne 1994), the case which was not achieved by the BGM operation (see Tables 4 and 5).

Table 5: Hydrocyclone performance indicators

\begin{tabular}{lllll}
\hline Parameter & S-1 & S-2 & S-3 & Design \\
\hline Feed rate $(\mathrm{t} / \mathrm{h})$ & 1729 & 1614 & 1061 & 1462 \\
Operating pressure $(\mathrm{kPa})$ & 98 & 81 & 92 & $80-110$ \\
Feed volume-\% solids & 42 & 44 & 41 & 33 \\
Underflow volume-\% solids & 57 & 57 & 56 & $48-56$ \\
Overflow volume-\% solids & 20 & 24 & 21 & $13-16$ \\
Feed $x_{\mathrm{P}, 80}(\mu \mathrm{m})$ & 768 & 771 & 570 & \\
Underflow $x_{\mathrm{P}, 80}(\mu \mathrm{m})$ & 963 & 1028 & 1127 & \\
Overflow $x_{\mathrm{P}, 80}(\mu \mathrm{m})$ & 266 & 288 & 241 & 125 \\
\hline
\end{tabular}

\section{Modal mineralogy}

Figure 4 presents the modal mineralogy of the three ore blends as determined with the MLA. Based on mineralogical reports of the deposit, gold and silver occur as inclusions in pyrite, inclusions in unaltered chalcopyrite, free grains, inclusions in quartz, and inclusions in bornite. Copper occurs primarily in the chalcocite-chalcopyrite replacement grains. Hence, pyrite-pyrrhotite is considered as the major gold-bearing mineral, and is therefore, the main phase of interest in this investigation. As can be seen from Figure 4, the gangue phases comprise mainly of quartz, feldspar, muscovite, biotite-chlorite and the phase "others" (i.e. epidote, fluorite, silicates, oxides and other minor sulphides). Furthermore, the feldspars phase in blends $\mathrm{S}-1$ and $\mathrm{S}-2$ is close. Also S-1 and S-3 have close biotile-chloride phase, while S-2 and S-3 have close muscovite phase.
For demonstration purposes, the modal mineralogy information in Figure 4 were supplemented with SEM images (i.e. Figure 5) for the ungrouped mineral phases and especially for the $200 \mu \mathrm{m}$ particles which could only be processed by MLA Dataview software (i.e. low particle count). In comparing the particle density (i.e. particle count/concentration) for each phase in Figure 5 , the result is in agreement with the modal mineralogy data presented in Figure 4 for all main phases presented (i.e. quartz, feldspars, muscovite, biotite-chlorite, and pyritepyrrhotite). For example, higher pyritepyrrhotite particle density was observed in S-1 followed by $\mathrm{S}-2$ and then by $\mathrm{S}-3$. Also, for the case of feldspars, higher particle density was observed in S-3 followed by S-1 and then by S2 . For the quartz, the particle density was noted to be close across the three samples. 


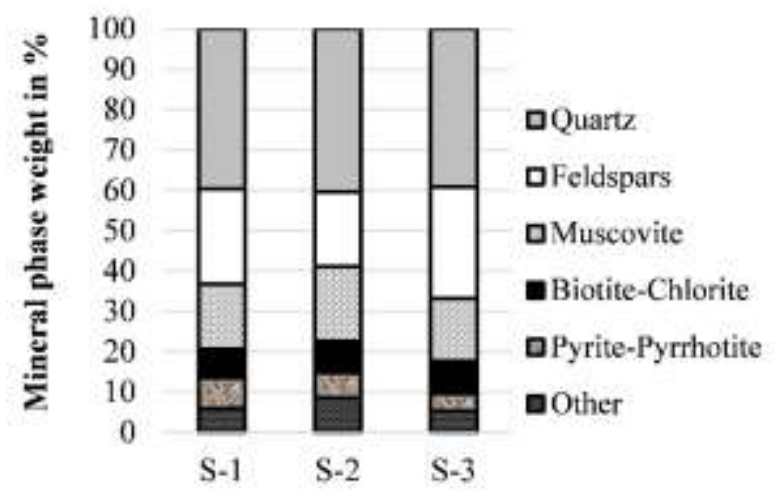

\section{Ore Blends}

Figure 4: Modal mineralogy of the three ore blends treated at BGM (wt. \%).

S-1

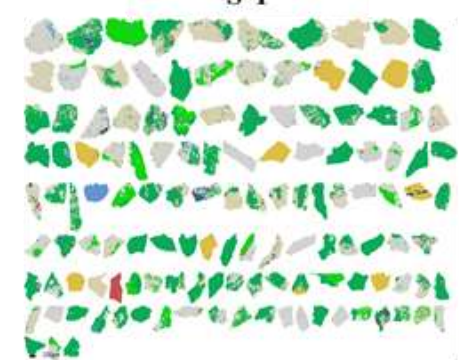

S-2

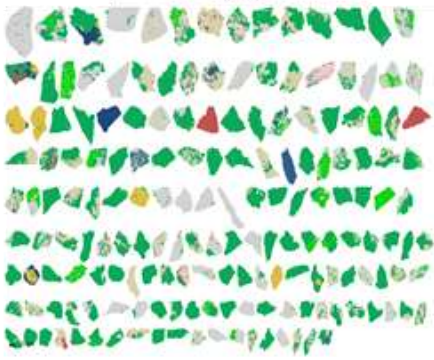

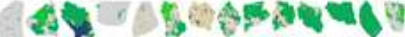

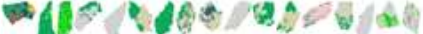

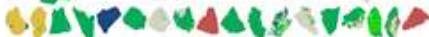

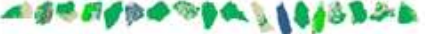
parafons

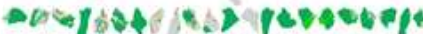

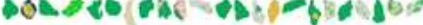

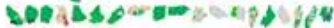
S-3

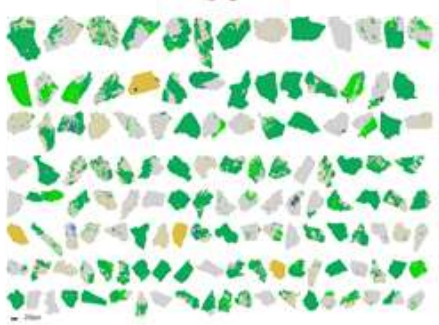

Au-Ag-Minerals Epidote

$\square$ Apatite-Phosphate Fluorite

Muscovite Sulfate-Carbonate Other sulfides

$\square$ Pyrite-Pyrrhotite

$\square$ Ti-Fe-Oxides

Other

Figure 5: SEM images for ungrouped mineral phases (i.e. $200 \mu \mathrm{m}$ particles).

Figure 6 shows the mineral grain size distribution of the major mineral phases for the three ore blends studied as determined by the MLA. In this study, all the particle size and mineral grain size measurements presented in this section are based on the Equivalent Circle
Diameter (ECD). Also, liberation (\% free mineral) is based on cumulative mass percentage of the mineral in the > $95 \%$ liberation class which is the common practice (Wang et al. 2012). 
In all cases, it can be seen that pyritepyrrhotite has the coarsest grain size distribution followed by quartz and feldspars. Moreover, the grain size distributions of quartz and feldspars closely follow the size distributions of the host particles. This implies
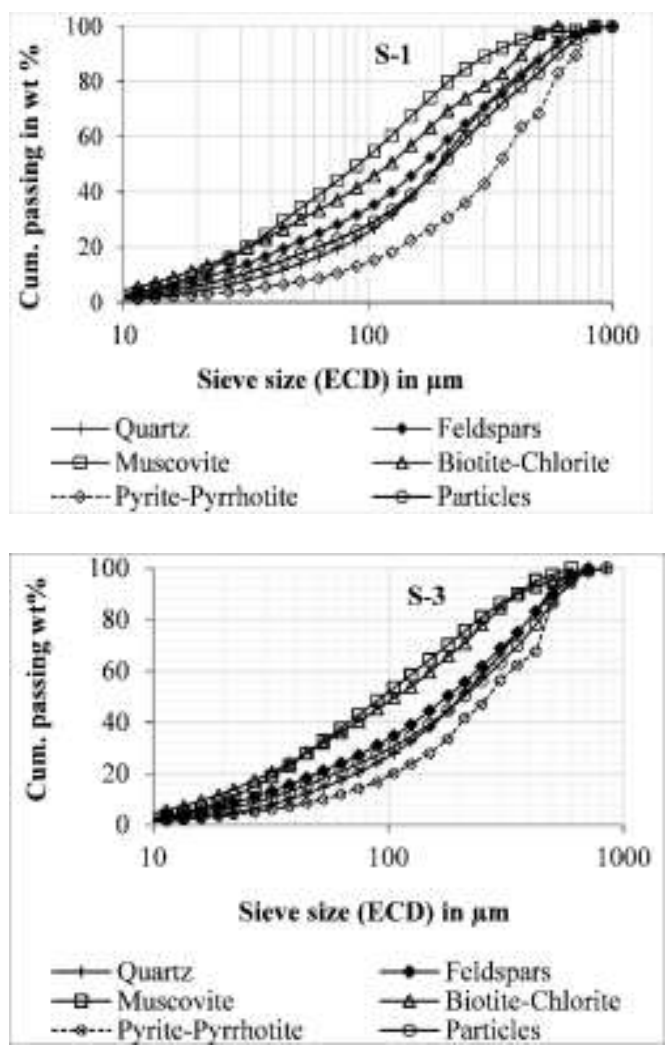

Figure 6: Particle and mineral grain size distributions for the three blends (S-1, S-2 and S-3).

From Figure 6, both trends indicate that pyrite-pyrrhotite mineral grain size is coarser than the size distribution of the host particles. It has to be understood that pyrite-pyrrhotite accounts for only a few percent of the material (see modal mineralogy in Figure 4). Hence, the distribution indicates that pyrite-pyrrhotite is bound to the larger particles of the population.

\section{Mineral liberation}

Since pyrite-pyrrhotite is the mineral phase of interest as it hosts gold, most of liberation studies in this work will concentrate on this that such minerals were better-liberated than others. Therefore, the results indicate that more milling energy is used in the grinding of gangue phases (quartz and feldspars) to finer sizes rather than grinding of the valuable pyrite-pyrrhotite mineral phase.

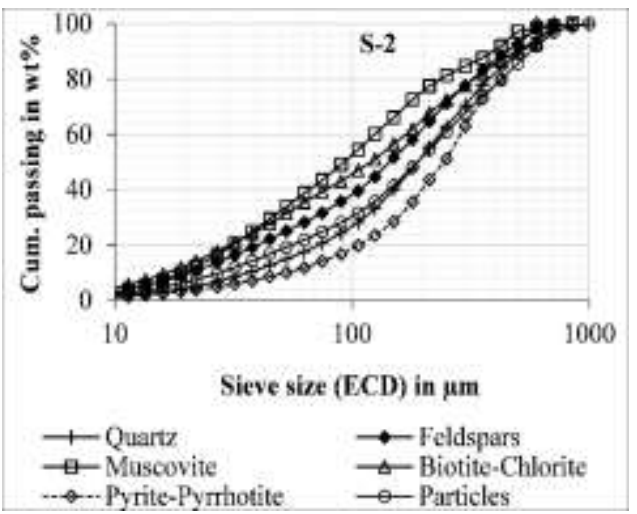

phase. The liberation of pyrite-pyrrhotite based on the five size fractions measured for each ore blend is shown in Figure 7. The trend is uniform for all the samples and shows that the degrees of liberation decrease with increase in particle sizes.

The degrees of liberation for S-1 and S-3 were close and higher than that of $\mathrm{S}-2$. Additionally, the degree of liberation for sample $\mathrm{S}-2$ in the fraction $500-1000 \mu \mathrm{m}$ is the lowest. This might be due to artefacts of poor particle statistics caused by the low grade of pyrite-pyrrhotite in the ore and the fine mineral 
grains (see Table 6). However, it is only divergent for the fraction $500-1000 \mu \mathrm{m}$, for all other size fractions of all samples; the degree of liberation for pyrite-pyrrhotite is higher than $75 \%$. This indicates that pyrite-pyrrhotite can be liberated at relatively very coarse sizes for the material investigated. Table 6 and Table 7 provide supplementary information on the particle statistics for clarification.

Table 6 : Pyrite-pyrrhotite particle counts for the fractions measured

\begin{tabular}{cccccc}
\hline Sample & \multicolumn{5}{c}{ Size class $(\mu \mathrm{m})$} \\
\cline { 2 - 6 } & $0-63$ & $63-125$ & $125-250$ & $250-500$ & $500-1000$ \\
S-1 & 5874 & 1054 & 551 & 245 & 727 \\
S-2 & 7107 & 1377 & 408 & 767 & 138 \\
S-3 & 4914 & 736 & 348 & 309 & 127 \\
\hline
\end{tabular}

In Figure 7, the errors on liberation measurements are also indicated and refer to the standard error calculated based on average liberation from the MLA measurements of three sample splits used for each fraction. It can be noted that the value of errors increases slightly with particle size. This is due to the decreasing number of particles or grains in the sample splits of these size classes. Except for the fraction 500-1000 $\mu \mathrm{m}$ of S-3, the errors are within tolerance for most of the fractions measured (i.e. $\pm 5 \%$ ) (Leigh et al. 1993). Another source of errors could be the epoxy stirring and cutting techniques that may result into inhomogeneous distribution of mineral grains in the epoxy, which can also contribute to differences in measured values. This section was also well covered in the authors' previous related work (Wikedzi et al. 2018) as had been introduced earlier.

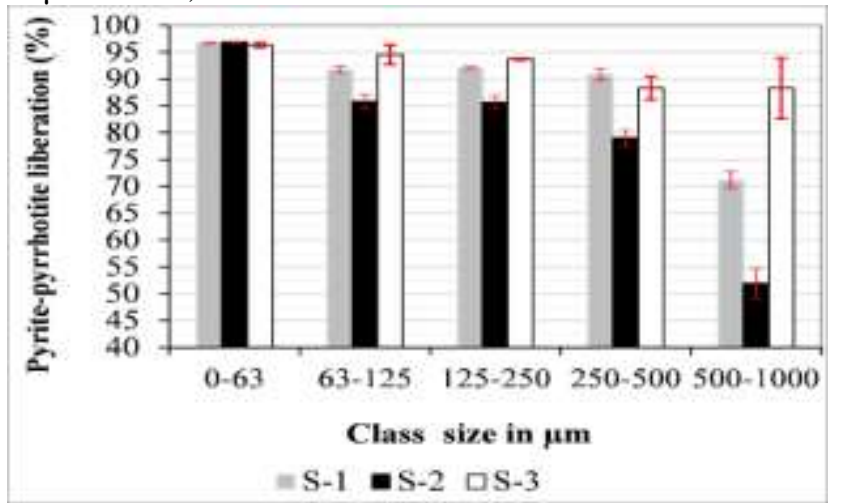

Figure 7: Liberation of pyrite-pyrrhotite based on sieved fractions (average of three measurements).

Table 7: Pyrite-pyrrhotite particle counts based on liberation classes for S-2

\begin{tabular}{lllllll}
\hline & \multicolumn{5}{c}{ Pyrite-pyrrhotite free surface of particle $(\%)$} \\
\cline { 2 - 7 } Class size $(\mu \mathrm{m})$ & $0-20$ & $20-40$ & $40-60$ & $60-80$ & $80-100$ & 100 \\
\hline $0-63$ & 93 & 19 & 29 & 20 & 15 & 6929 \\
$63-125$ & 33 & 9 & 7 & 7 & 28 & 1288 \\
$125-250$ & 24 & 2 & 5 & 3 & 14 & 350 \\
$250-500$ & 30 & 7 & 6 & 4 & 37 & 648 \\
$500-1000$ & 9 & 2 & 0 & 1 & 0 & 121 \\
\hline
\end{tabular}


Figure 8 shows pyrite-pyrrhotite cumulative liberation in relation to class mean particle size. It is seen that all samples had liberation $>80 \%$. Hence, it can be concluded that pyritepyrrhotite could be economically liberated at significantly coarse size (approx. 200-400 $\mu \mathrm{m}$ ), corresponding to cumulative liberation $>85 \%$ for all the samples. This can further be deduced that if milling at BGM could have been followed by a gravity concentration alone, the grinding costs could have possibly been saved as the materials indicate less milling requirement in order to achieve liberation of the valuable phase. However, this could be confirmed through lab scale gravity concentration tests.

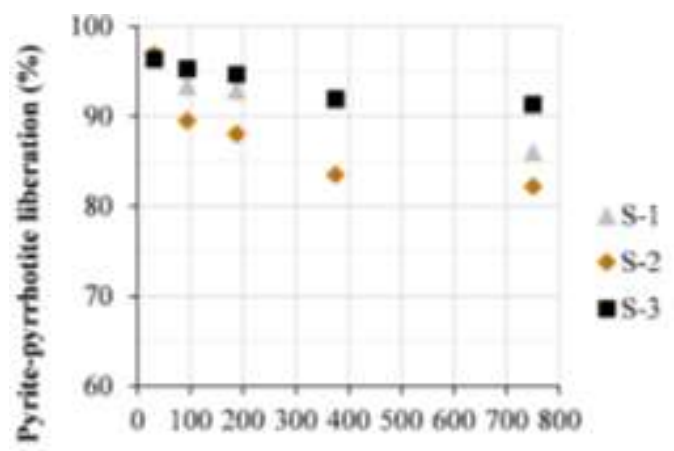

Class mean particle sire (ECD) in $\mu \mathrm{m}$

Figure 8: The relationship between cumulative pyrite-pyrrhotite liberation and class mean particle size.

Figure 9 presents the enrichment characteristics of pyrite-pyrrhotite in relation with particle size. The enrichment parameter (commonly termed as enrichment ratio, $E_{\mathrm{R}}$ ) is important as is used in determining the mineral liberation size required for a given operation and hence the extent of grinding (mesh of grind) necessary for an efficient mineral beneficiation process. In this case, the parameter was calculated as the ratio of the grade or content of pyrite-pyrrhotite in a given size fraction $\left(m_{\mathrm{xi}}\right)$ to that in the feed sample $\left(m_{\mathrm{x}}, \mathrm{F}, \mathrm{Eq} .(1)\right)$ and demonstrates that much of pyrite-pyrrhotite was enriched in the size range 250-500 $\mu \mathrm{m}$.

$$
E_{R}=\left(\frac{m_{x i}}{m_{x, F}}\right)
$$

Sample S-2 had the highest enrichment in this size range followed by sample S-3 and sample S-1. Surprisingly, sample S-1, shows higher enrichment even at coarsest size fraction.

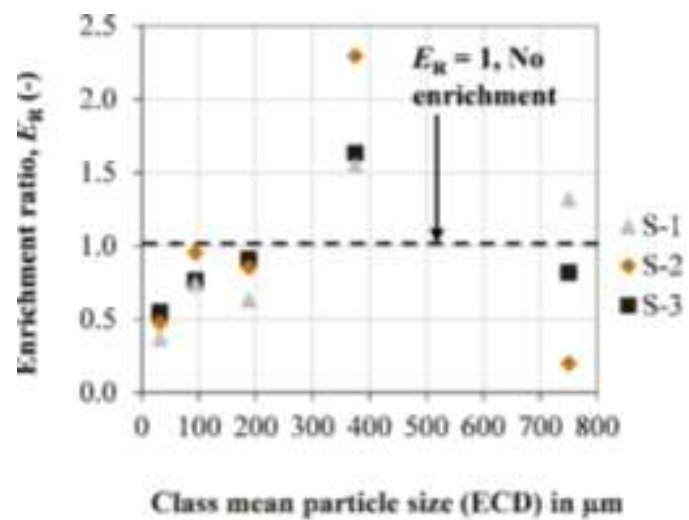

Figure 9: Pyrite-pyrrhotite enrichment in relation with particle size.

The extent of milling required (mesh of grind) for a given material can be decided by assessing the relationship between degree of mineral liberation and respective mineral grain size. This important aspect was also evaluated in this study. Figure 10 presents the relationship between pyrite-pyrrhotite cumulative liberation with its geometric mean grain size. 


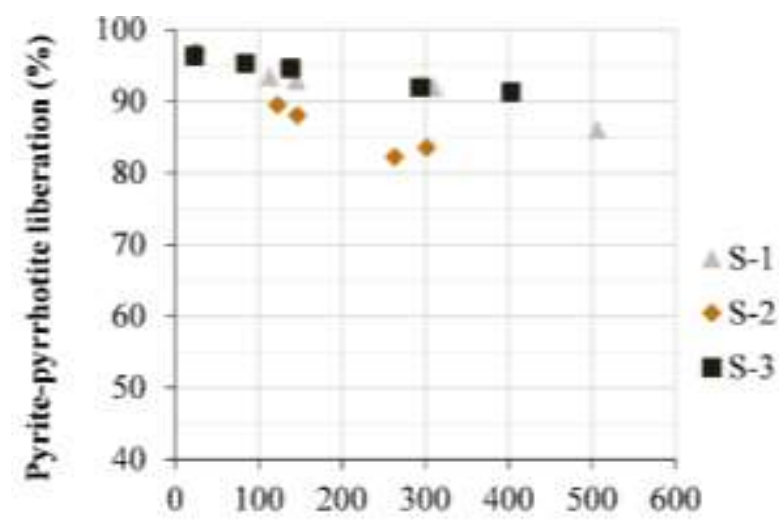

Geometric mean grain size (ECD) in $\mu \mathrm{m}$

Figure 10: Pyrite-pyrrhotite cumulative liberation for the three samples as a function of geometric mean grain size.

From Figure 10, it can be seen that S-3 has coarser mineral grain size compared to $\mathrm{S}-1$ and $\mathrm{S}-2$. Pyrite-pyrrhotite liberation increases with decrease in mineral grain size for all samples. This implies that less milling is required in order to liberate pyrite-pyrrhotite from sample $\mathrm{S}-3$ (i.e. coarsest mineral grain size) as compared to S-1 and S-2 (finer mineral grain size). This is in agreement with the higher pyrite-pyrrhotite liberation displayed previously in Figure 7 and Figure 8.

The degree of fineness of the sieved fractions used for automated SEM measurements in relation to the size before preparation by milling (i.e. feed to the screen mill in this case) can be determined by calculating the so called reduction ratio $(R R)$. This is the ratios of geometric mean sizes of the feed $\left(G_{m}(X i, F)\right.$ to that of the sieved fractions feed $\left.\left(\mathrm{G}_{\mathrm{m}(\mathrm{Xi}, \mathrm{P})}\right)\right)$ (Eqn.(2)).

$$
R R=\left(\frac{G_{m(x i, F)}}{G_{m(x i, P)}}\right)
$$

The reduction ratio in this case was determined for the three samples and related to cumulative pyrite-pyrrhotite liberation as shown in Figure 11. It is seen that S-3 had the highest reduction ratio than $S-1$ and $S-2$. This suggests that S-3 sieved fractions were finer than those for S-1 and S-2. Also, pyritepyrrhotite liberation increases with increase in reduction ratio, with S-3 giving higher liberation than S-1 and S-2 due to more fineness of material for sample S-3 than other samples. Consequently, it can be established that the better pyrite-pyrrhotite liberation achieved for S-3 fractions was also influenced by their fineness.

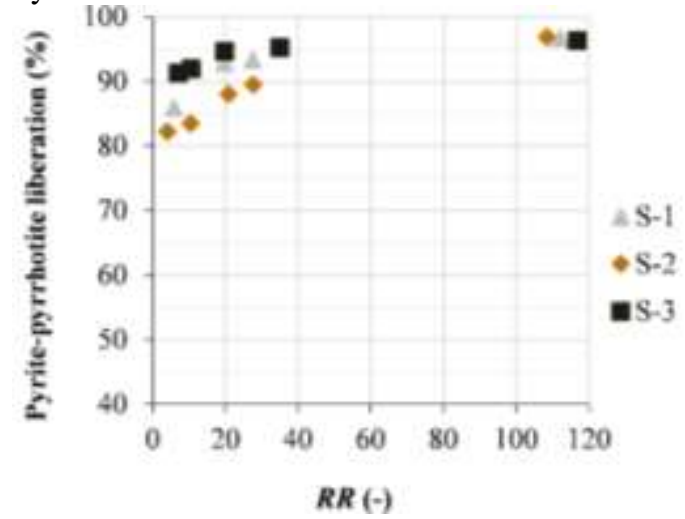

Figure 11: Pyrite-pyrrhotite cumulative liberation for the three samples as a function of reduction ratio $(\mathrm{RR})$.

\section{Mineral locking}

Figure 7 already revealed that pyritepyrrhotite fractional liberation was $>80 \%$ for 
all the samples investigated. Therefore, only $20 \%$ of pyrite-pyrrhotite was unliberated (locked to other mineral phases). Thus, the proportion into which the valuable mineral phase, pyrite-pyrrhotite is locked to different mineral phases is presented in Figure 12 through Figure 14.

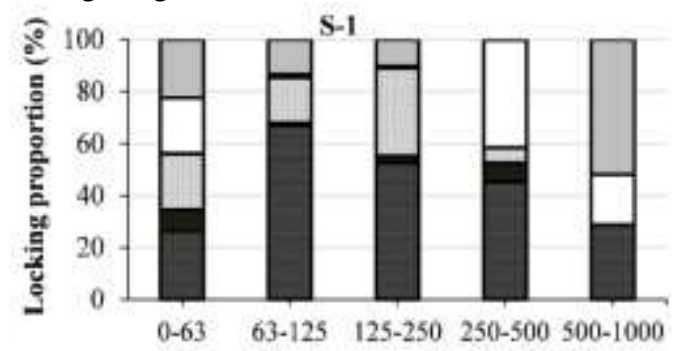

Size class in $\mu \mathrm{m}$

\section{ather Biotite-Chlorite aMuscovite} aFeldspars aQuartz

Figure 12: Pyrite-pyrrhotite locking as a function particle size, $S-1$.

From Figure 12 through Figure 14, it is seen that there is no consistent trend defining the extent to which pyrite-pyrrhotite is locked to different minerals with respect to the particle size. For most of the fractions in all samples, pyrite-pyrrhotite is locked into the phase "other", followed by muscovite or quartz and feldspars phases. The extent into which pyritepyrrhotite is locked into the phase "other" is almost comparable in all fractions for S-2, as opposed to the fluctuations observed for S-1 and S-3. Likewise, pyrite-pyrrhotite locking into quartz and muscovite varies significantly between fractions in all the samples. To recall, the mineral group "other" comprises of the phases epidote, fluorite, silicates, oxides and other minor sulphides. Therefore, it can be assumed that the group "other" is where pyritepyrrhotite was mainly locked to for the investigated orebody.

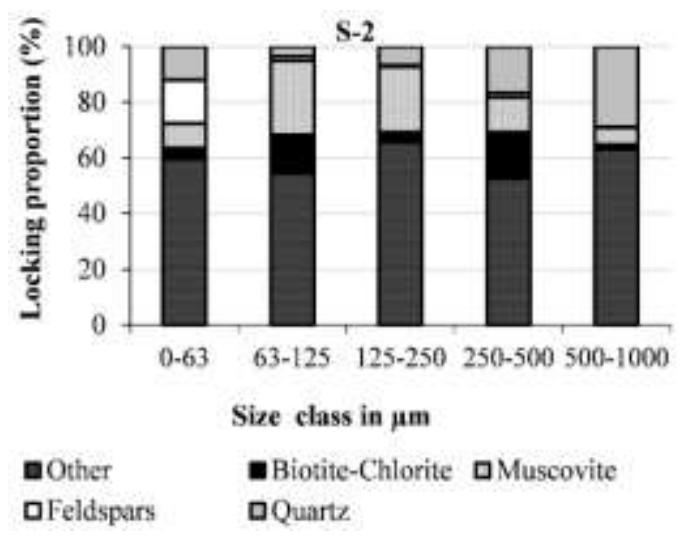

Figure 13: Pyrite-pyrrhotite locking as a function of particle size, S-2.

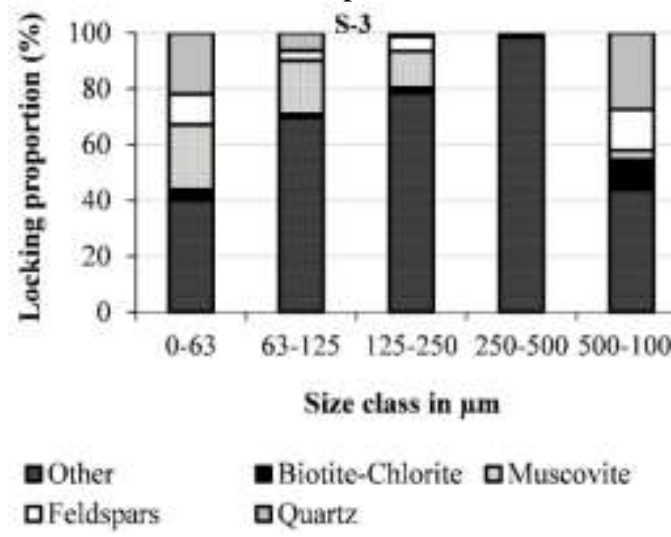

Figure 14: Pyrite-pyrrhotite locking as a function of particle size, S-3.

\section{Conclusions and Recommendations}

The mineral liberation studies of three gold ore blends treated at Buzwagi Gold Mine revealed that pyrite-pyrrhotite is the major valuable mineral in the material with quartz, feldspar, muscovite and biotite-chlorite being the gangue minerals. The mineral grain sizes distribution of quartz and feldspars closely follow the particle size distribution of the host particles. Therefore, those minerals show a good liberation from the others. Most of the pyrite-pyrrhotite mineral phases could be enriched in the size range 250-500 $\mu \mathrm{m}$ with $\mathrm{S}-2$ having the highest enrichment followed by S-3 and S-1. Therefore, for efficient beneficiation process, grinding of the ore to such fineness is necessary. Pyrite-pyrrhotite shows a coarser 
grain size distribution compared to most gangue minerals present. This implies that, when grinding the ores, most of the milling energy is applied in the grinding of the gangue phases instead of the valuable phase. Pyritepyrrhotite is liberated at relatively coarse size (i.e. approx. 200-400 $\mu \mathrm{m}$ ), with > $85 \%$ cumulative liberation for each sample. This is good for the gravity circuit efficiency only. However, the efficiency of flotation and cyanidation processes will still require finer feed contrary to what was observed from the survey data on the cyclone overflow (i.e. $\mathrm{X}_{\mathrm{P}, 80}$ $>200 \mu \mathrm{m}$ vs. $125 \mu \mathrm{m}$ (target)). Based on the MLA results, the gold host phase (pyritepyrrhotite) indicated a significant degree of liberation at coarser sizes. However, for the benefits of downstream operations (flotation and leaching), understanding the grain sizes of the minerals to be recovered (e.g. gold and silver) could add more knowledge especially on their liberation size, giving guidance on the extent of grinding required. Due to limitations of automated mineralogy measurements used in the study, the mineralogical information for gold (e.g. grain size, grade, etc.) could not be obtained. Hence, in order to achieve this, further studies may be conducted through applications of advanced mineral characterization methods such as QEMSCAN Trace Mineral Search (TMS). Lab-scale gravity concentration and flotation tests are recommended for better understanding of the mineral liberation results revealed.

\section{Acknowledgements}

The authors thank Buzwagi Gold Mine for the opportunity to conduct this study. The Department of Mineralogy, TU Bergakademie Freiberg is also acknowledged for preparation and measurements of mineral liberation for the materials.

\section{References}

Baum W 2014 Ore characterization, process mineralogy and lab automation a roadmap for future mining. Miner. Eng. 60: 69-73.

Baum W, Lotter NO and Whittaker PJ 2004
Process mineralogy-a new generation for ore characterisation and plant optimisation. SME Annual Meeting No. 04-12, pp. 23-25.

Bérubé MA and Marchand JC 1984 Evolution of the mineral liberation characteristics of an iron ore undergoing grinding. Int. J. Miner. Process. 13: 223-237.

Danha G 2013 Identifying Opportunities for Increasing the Milling Efficiency of a Bushveld Igneous Complex (BIC) Upper Group (UG) 2 Ore. University of Witwatersrand.

Evans CL, Wightman EM, Manlapig EV and Coulter BL 2011 Application of process mineralogy as a tool in sustainable processing. Miner. Eng. 24: 1242-1248.

Fandrich R, Gu Y, Burrows D and Moeller K 2007 Modern SEM-based mineral liberation analysis. Int. J. Miner. Process. 84: 310-320.

Gottlieb P, Wilkie G, Sutherland D, Ho-Tun E, Suthers S, Perera K, Jenkins B, Spencer S, Butcher A and Rayner J 2000 Using quantitative electron microscopy for process mineralogy applications. Jom 52: 24-25.

Gu Y 2003 Automated scanning electron microscope based mineral liberation analysis: An introduction to JKMRC/FEI mineral liberation analyser. J. Miner. Mater. Charact. Eng. 2, 33-41.

Hoal KO, Stammer JG, Appleby SK, Botha J, Ross JK and Botha PW 2009 Research in quantitative mineralogy: Examples from diverse applications. Miner. Eng. 22: 402408.

Leigh GM, Sutherland DN and Gottlieb P 1993 Confidence limits for liberation measurements. Miner. Eng. 6: 155-161.

Leißner T, Hoang DH, Rudolph M, Heinig T, Bachmann K, Gutzmer J, Schubert H and Peuker UA 2016 A mineral liberation study of grain boundary fracture based on measurements of the surface exposure after milling. Int. J. Miner. Process. 156: 3-13.

Lotter NO 2011 Modern process mineralogy: an integrated multi-disciplined approach to flowsheeting. Miner. Eng. 24: 1229-1237. 
Morrell S 1996 Power draw of wet tumbling mills and its relationship to charge dynamics-Part 2: An empirical approach to modelling of mill power. Trans. Instn Min. Metall. 105: C54-C62.

Napier-Munn TJ, Morrel S and Kojovic T 1996 Mineral Comminution Circuits: Their Operation and Optimisation, JKMRC Monograph Series in Mining and Mineral Processing 2. JKMRC, Queensland.

O'connor CT and Dunne R 1994 The flotation of gold bearing ores- a review. Miner. Eng. 7: 839-849.

Sandmann D 2015 Method development in automated mineralogy. der Fak. für Geowissenschaften, Geotech. und Bergbau. der Technischen Universität Bergakademie Freiberg.

Sandmann D and Gutzmer J 2013 Use of mineral liberation analysis (MLA) in the characterization of lithium-bearing micas. J. Miner. Mater. Charact. Eng. 1: 285-292.

Smythe DM, Lombard A and Coetzee LL 2013 Rare Earth element deportment studies utilising QEMSCAN technology. Miner. Eng. 52: 52-61.

Ueda T, Oki T and Koyanaka S 2018 Experimental analysis of mineral liberation and stereological bias based on X-ray computed tomography and artificial binary particles. Adv. Powder Technol. 29: 462470.

Ueda T, Oki T and Koyanaka S 2017 Comparison of seven texture analysis indices for their applicability to stereological correction of mineral liberation assessment in binary particle systems. Miner. 7(11): 222

Veasey TJ and Wills BA 1991 Review of methods of improving mineral liberation. Miner. Eng. 4: 747-752.

Vizcarra TG, Wightman EM, Johnson NW and Manlapig EV 2010 The effect of breakage mechanism on the mineral liberation properties of sulphide ores. Miner. Eng. 23: 374-382.

Wang E, Shi F and Manlapig E 2012 Mineral liberation by high voltage pulses and conventional comminution with same specific energy levels. Miner. Eng. 27: 2836.

Wang Y, McClung C, Lin CL and Miller JD 2018 Stereological correction of perimeter based estimates of exposed grain surface area. Miner. Eng. 126: 64-73.

Wikedzi A 2018 Optimization and performance of grinding circuits: The case of Buzwagi Gold Mine (BGM). TU Bergakademie Freibergy.

Wikedzi A, Arinanda MA, Leißner T, Peuker UA and Mütze T 2018 Breakage and liberation characteristics of low grade sulphide gold ore blends. Miner. Eng. 115: 33-40.

Wills BA and Finch JA 2016 Wills' Mineral Processing Technology: An Introduction to the Practical Aspects of Ore Treatment and Mineral Recovery. Elsevier, Oxford. 